\title{
PERENCANAAN DAN PERANCANGAN TAMAN WISATA KULINER DI KABUPATEN ENREKANG
}

\author{
Burhanuddin ${ }^{*}$,St Aisyah Rahman ${ }^{2}$ Intan Sakinah ${ }^{3}$ \\ Jurusan Arsitektur Fakultas Sains dan Teknologi UIN Alauddin Makassar \\ e-mail: ${ }^{1}$ amin.burhanuddin@gmail.com, ${ }^{2}$ aisysipala@gmail.com,intansakinah@gmail.com
}

\begin{abstract}
Abstrak_ Potensi kuliner Kabupaten Enrekang menjadi perhatian pemerintah terhadap pengembangan pariwisata sangat besar terutama pada jalur menuju Tanatoraja. Maka diperlukan sebuah perancangan taman wisata kuliner di Enrekang. Metode yang digunakan ialah metode desktriptif melalui studi literatur, studi preseden, dan studi lapangan dengan melakukan survey langsung ke lapangan untuk mengamati dan menganalisis lingkungan sekitar tapak. Perancangan menggunakan konsep Arsitektur Kontemporer berupa konsep perancangan dalam merancang kawasan taman wisata kuliner, terdiri dari: zoning/ peruntukan lahan (land use), bentuk dan massa bangunan (building from and massing), sirkulasi dan parkir (circulation and parking), jalur pejalan kaki (pedestrian ways), ruang terbuka (open space), dan penanda (signage).
\end{abstract}

Kata kunci : Wisata Kuliner, Konsep Koneporer, Enrekang.

\begin{abstract}
Culinery's Potency in Enrekang Regency is the government's attention to the enormous tourism development especially on the path to go to Tanatoraja. In this case, it is needed a design of culinary tourism area in Enrekang. The method used is descriptive method through literature study, precedent study, and field study by conducting direct survey to the field to observe and analyze the environment around the site. The design using the concept of Contemporary Architecture includedof design concept in designing culinary tourism area, consists of: zoning / land use (land use), shape and building mass (building from and massing), circulation and parking (circulation and parking), pedestrian path (pedestrian ways), open space (space), and signage (signage).
\end{abstract}

Keywords: Culinary Tour, Concept of Koneporer, Enrekang.

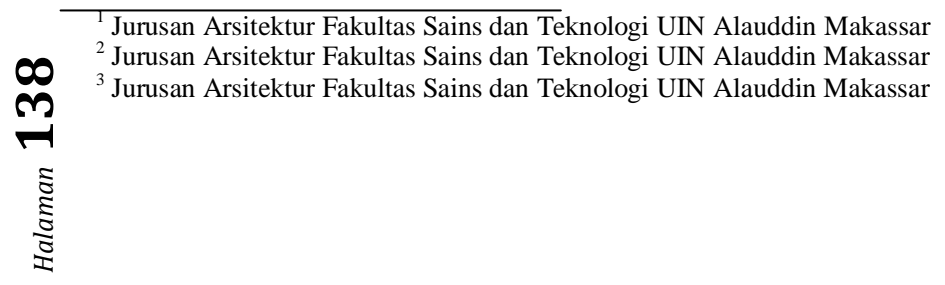




\section{PERENCANAAN DAN PERANCANGAN TAMAN WISATA KULINER DI KABUPATEN ENREKANG}

\section{PENDAHULUAN}

Kabupaten Enrekang merupakan salah satu Kabupaten yang terletak di Provinsi Sulawesi Selatan yang memiliki luas 1.786,01 km, terdiri atas 12 kecamatan. Enrekang masuk dalam kawasan pengembangan pariwisata "Sawerigading" Sulawesi Selatan, bersama Kabupaten Luwu, Kota Palopo, Luwu Utara, dan Luwu Timur. Daerah yang masuk dalam satukawasan wisata ini memiliki kesamaan budaya dan seni "tempo doeloe".(Hidri, 2010:2-3). Selain itu Kabupaten Enrekang memiliki banyak potensi wisata salah satunya adalah wisata kuliner. Makanan andalah Enrekang adalah Dangke. Dangke adalah salah satu makanan tradisional Enrekang yang sudah dikenal luas, bahkan telah memiliki hak paten (http://makassar.antaranews.com, 2015). Selain Dangke makanan tradisional lain yang menjadi andalan yaitu Nasu Cemba, Sokko Pulu Mandoti, Sokko Ubi Kayu, Deppa Tetekan, Baje Kotu, Nasi Singkong, Songkolo Singkong, Bassang, Barobo, Jewawut dan berbagai jenis makanan khas Enrekang. Potensi ini perlu dikembangkan mengingat Enrekang menjadi jalur utama perjalanan wisatawan menuju Tanatoraja.

Untuk mendukung langkah Pemerintan Kabupaten Enrekang maka perlu adanya tempat wisata kuliner agar masyarakat dan wisatawan yang berkunjung tidak merasa bingung mencari lokasi pusat kuliner yang menyediakan makanan khas daerah Enrekang.

Lokasi wisata kuliner yang direncanakan terletak di kawasan pegunungan Bambapuang, tepatnya di Desa Mendatte Kecamatan Anggeraja Kabupaten Enrekang. Lokasi ini dipilih karena beberapa alasan seperti akses menuju lokasi sangat mudah, selain itu berada di depan jalan poros Makassar-Tator dan hal utama dalam pemilihan lokasi adalah suasana yang ditawarkan sekitar lokasi masih asri dengan panorama indah Gunung Nona dan Gunung Bambapuang yang sudah di kenal sampai ke mancanegara.

Diharapkan dengan adanya kawasan kuliner ini dapat menjadi kawasan wisata kuliner yang menyuguhkan makanan khas daerah dan menjadi daya tarik wisata Kabupaten Enrekang. Apalagi Pemkab Enrekang telah mengembangkan wisata kuliner ke dalam industri pariwisata untuk menarik kunjungan wisatawan mancanegara maupun domestik (http://makassar.antaranews.com, 2015). Untuk itu perlu dibuat sebuah usaha untuk meningkatkan potensi ekonomis ini dengan memberikan sentuhan dan dukungan untuk dapat menarik wisatawan lokal atau asing agar tertarik menikmati kuliner asli daerah. Agar lebih menarik maka dalam perencanaan, konsep yang akan digunakan yaitu kontemporer.

Kontemporer dalam Kamus Lengkap Bahasa Indonesia (2013:334) berarti Pada waktu atau masa yang sama, pada masa kini. Kontemporer merupakan suatu aliran arsitektur yang terus berkembang dari waktu ke waktu mengikuti perkembangan zaman yang bersifat kekinian. Konsep kontemporer dipilih karena bersifat modern yang menyesuaikan dengan perkembangan arsitektur masa kini dimana modernisasi dan globalisasi semakin mempengaruhi. Menurut A'raaf (2012:86) ada delapan elemen perancangan kota sebagai pedoman dalam merancang sebuah kota yaitu: Land Use, Building From and Massing, Circulation and Parking, Open Space, Pedestrian Ways, Activity Support, Signage, Preservation.

Berdasarkan pertimbangan-pertimbangan diatas, perencenaan dan perancangan Taman Wisata Kuliner Lokal Konsep Kontemporer di Enrekang, diharapkan menjadi pusat wisata kuliner yang menyediakan makanan khas Enrekang yang dapat dinikmati oleh masyarakat sekitar maupun bagi wisatawan lokal/mancanegara yang memang berkunjung ke Enrekang maupun yang hanya melewati Kabupaten Enrekang. Diharapkan dengan adanya pusat kuliner ini akan mampu meningkatkan kondisi perekonomian daerah. 


\section{METODE}

Metode yang digunakan ialah metode deskriptif. Menurut Nazir (1988), metode deskriptif merupakan suatu metode dalam meneliti status sekelompok manusia, suatu objek, suatu kondisi, suatu system pemikiran ataupun suatu kelas peristiwa pada masa sekarang. Sedangkan menurut Sugiyono (2005) menyatakan bahwa metode deskriktif suatu metode yang digunakan untuk menggabarkan atau menganalisis suatu hasil penelitian tetapi tidak digunakan untuk membuat kesimpulan yang lebih luas, menurut Whitney (1960), metode deskriptif (1960) metode deskriptif adalah pencarian fakta dengan interpretasi yang tepat. adapun studi yang dilakukan meliputi :

1. Studi Literatur

Pada tahap ini penulis mengambil studi literatur dari buku-buku perpustakaan dan bukubuku lain yang berkaitan dengan judul untuk mendapatkan teori, spesifikasi, dan karakteristik, serta aspek-aspek arsitektural yang dapat dijadikan landasan dalam proses perancangan.

2. Studi Banding / Studi Preseden

Pada tahap ini penulis mengambil studi banding melalui survey dan studi preseden melalui internet terhadap pengembangan kawasan yang ada di Indonesia.

3. Studi Lapangan

Pada tahap ini penulis melakukan survey langsung ke lapangan untuk mengamati dan menganalisis lingkungan sekitar tapak guna menunjang dalam perencanaan.

\section{HASIL DAN PEMBAHASAN}

\section{A. Zoning/ Peruntukan Lahan (Land Use)}

Penggunaan lahan di lokasi penelitian memiliki jenis penggunaan lahan yang beragam yaitu permukiman, kawasan wisata alam, perdagangan, hutan, kebun/ladang dan lahan kosong berupa semak belukar. Untuk penggunaan lahan disekitar kawasan dapat dilihat pada gambar dibawah ini.

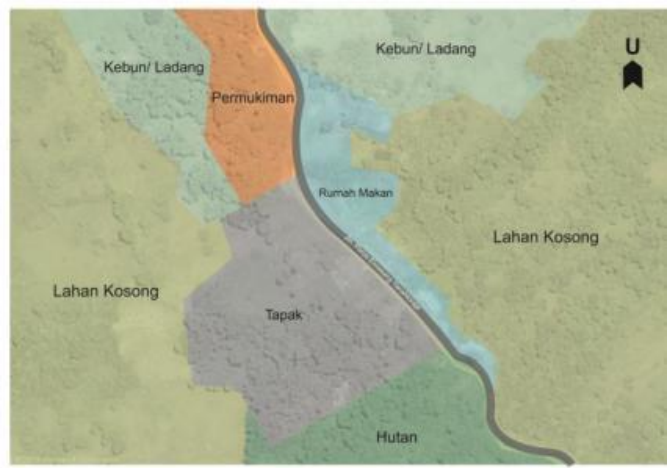

Gambar 1 : Penggunaan Lahan di Lokasi Perencanaan Sumber : Olah Data Lapangan, 2015 
Zoning kawasan dibagi menjadi tiga yaitu:

a. Zona publik pada lokasi tapak memiliki fungsi yakni sebagai tempat destinasi wisata alam gunung Bambapuang dan gunung Nona.

b. Zona semi publik pada sekitar tapak yaitu area perdagangan berupa rumah makan dan warung/kios. Selain itu disekitar tapak sebagian besar merupakan lahan kosong yang banyak dimanfaatkan oleh warga sekitar sebagi kebun/ladang sehingga sifat lahan dianggap semi publik.

c. Zona privat adalah area pribadi warga yang bermukim dekat dengan lokasi tapak. Tingkat kepadatan bangunan sendiri sangat rendah karena adanya jarak yang cukup antara rumah warga denga rumah lainya.

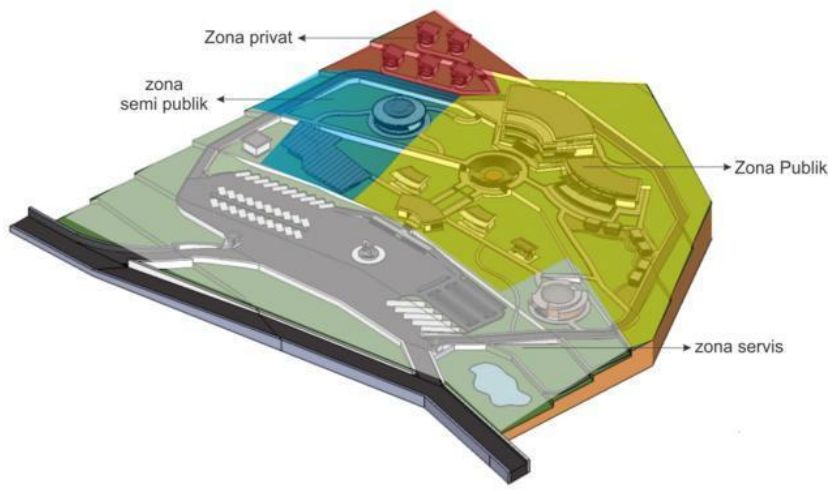

Gambar 2. Zoning kawasan (Sumber: Olah Desain, 2016)

Kondisi tofografi tapak yang berkontur memiliki beberapa potensi dan hambatan yang dapat mempengaruhi dalam proses perancangan. Adapun potensi Ketinggian tanah pada lokasi tapak bisa menambah view dari dan keluar tapak. Perlu perencanaan yang baik dalam menentukan perletakan massa bangunan untuk meminimalkan cut and file pada site. Pengolahan kontur pada tapak memerlukan teknik khusus dalam penataannya. Teknik yang digunakan ialah membuat dinding penahan tanah untuk mencegah pergerakan tanah. Kemudian dilakukan proses penimbunan (Fill) dan pengerukan/penggalian (Cut) untuk perletakan massa bangunan.

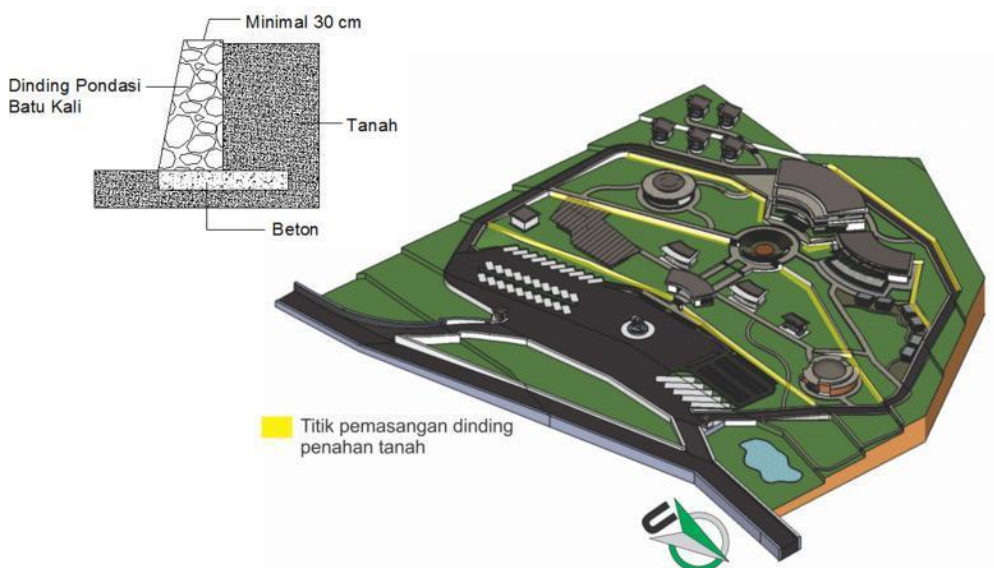

Gambar 3. Titik pemasangan dinding penahan tanah (Sumber: Olah Desain, 2016) 


\section{B. Massa Bangunan}

Building Form and massing menurut Shirvani (1985) ialah membahas mengenai bagaimana bentuk dan massa-massa bangunan yang ada dapat membentuk suatu kota serta bagaimana hubungan antar massa yang ada. Pada penataan suatu kota, bentuk dan hubungan antara massa seperti ketinggian bangunan, pengaturan massa bangunan dan lain-lain haru diperhatikan sehingga ruang yang terbentuk teratur, mempunyai garis langit yang dinamis serta menghindari adanya lost space (ruan tidak terpakai). Building Form and massing pada perancangan ini menggukan KDB (Koifisien Dasar Bangunan) 20\% Terbangun direncanakan dan $80 \%$ Tidak terbangun direncanakan dengan luas site yang tersedia adalah $24.000 \mathrm{~m} 2(2,4$ $\mathrm{Ha})$.

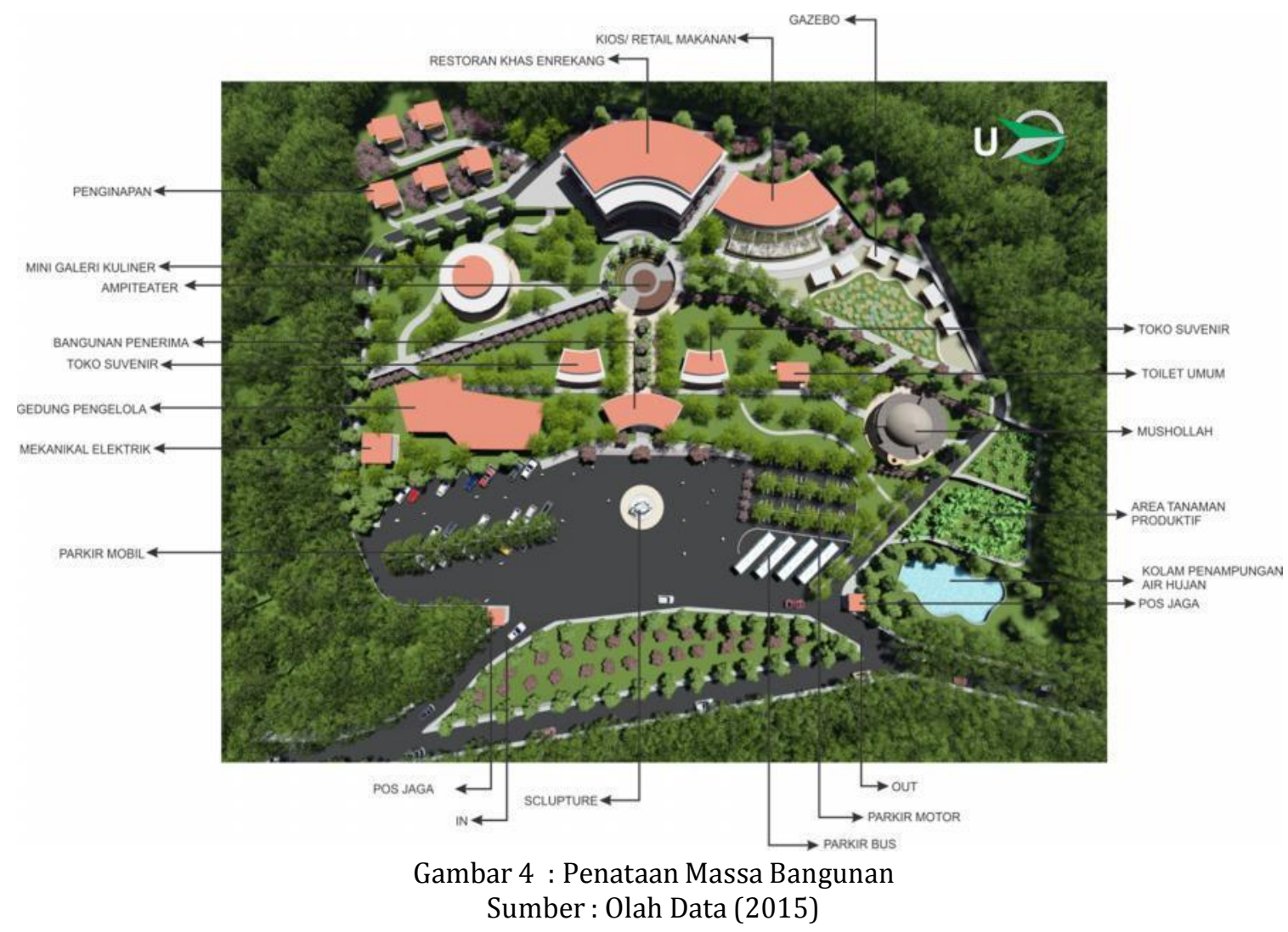

\section{Sirkulasi dan Parkir (Circulation and Parking)}

Sirkulasi adalah elemen perancangan kota yang secara langsung dapat membentuk dan mengontrol pola kegiata kota, sebagaimana halnya dengan keberadaan sistem transportasi dari jalan publik, pedestrian dan tempat-tempat transit. Sirkulasi dianalisis untuk mengetahui dari dan menuju tapak. Berdasarkan hasil pengamatan sirkulasi didepan tapak sangat sibuk mengingat jalan di depan tapak adalah jalan poros Enrekang yang dilalui kendaraan menuju ke Tanahtoraja dan wilayah Duri. Oleh karena itu, perlu pemikiran mendasar antara prasarana jalan yang tersedia, bentuk struktur kawasan, fasilitas pelayanan umum dan jumlah kendaraan yang semakin meningkat tiap tahunnya. 
Tempat parkir mempunyai pengaruh langsung pada suatu lingkungan yaitu pada kegiatan komersial di daerah perkotaan dan mempunyai pengaruh visual pada beberapa daerah perkotaan.

Area parkir yang dirancang pada tapak dibedakan menjadi tempat parkir mobil, bus, dan sepeda motor. Parkir pengunjung dan pengelola tidak dibuat terpisah. Sedangkan untuk kendaraan servis berupa mobil barang tidak tersedia karena disesuaikan dengan fungsi kendaraan yang hanya datang membawa dan meletakkan lalu pergi.

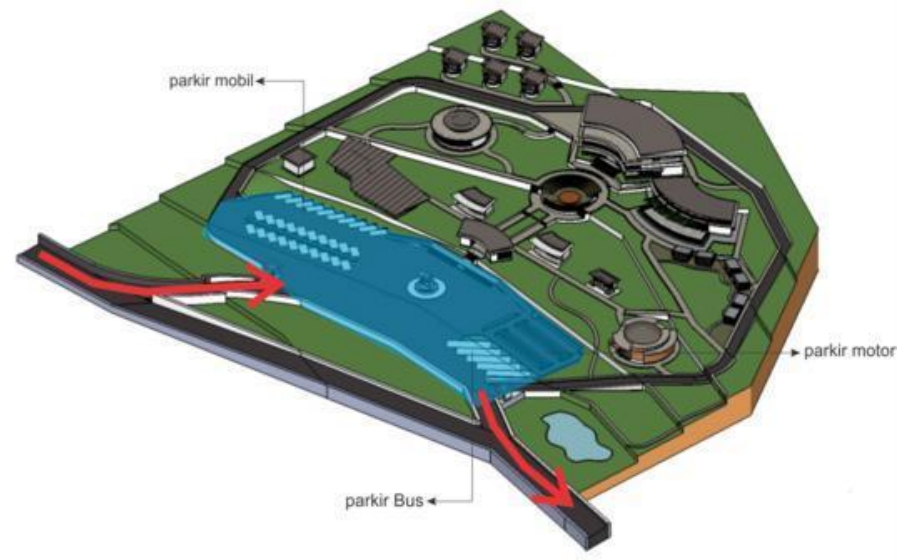

Gambar 6 : Parkir kendaraan di sekitar tapak

(Sumber : Olah data lapangan, 2015)

\section{Jalur Pejalan Kaki (Pedestrian Ways)}

Desain pedestrian kawasan taman wisata kuliner menggunakan material dari material keras buatan kombinasi (Composite Material) dan material keras alami dari potensi geologi (Inorganic Materials Used In Their Natural State).

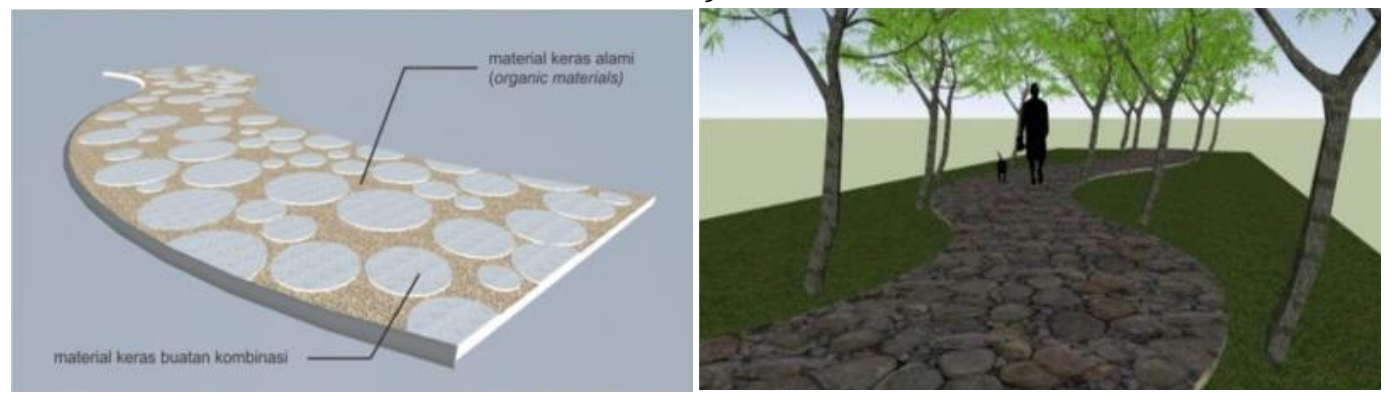

Gambar 7 : Jalur Pejalan Kaki

(Sumber : Olah data lapangan, 2015)

\section{E. Ruang Terbuka (Open Space)}

Ruang terbuka pada kawasan taman wisata kuliner di Enrekang mengalami beberapa perubahan dengan adanya penambahan vegetasi serta perubahan bentuk lansekap pada kawasan. 


\section{F. Penanda (Signage)}

a. Gerbang kawasan

Bentuk gerbang kawasan diambil dari filosofi bentuk piring yang berbentuk lingkaran. Material yang digunakan dari material keras buatan kombinasi (Composite material).

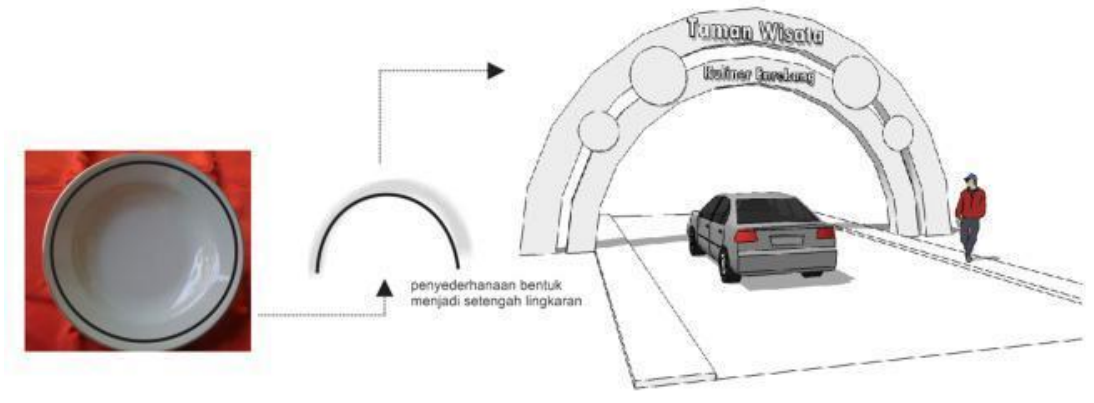

Gambar 8 : Gerbang Kawasan

(Sumber : Olah desain, 2016)

b. Penunjuk arah/nama dari lokasi tertentu.

Penanda untuk peta kawasan dan penunjuk arah dan area tertentu dalam taman wisata kuliner di Enrekang mengadopsi bentuk piring. Material yang digunakan dari material keras buatan kombinasi (Composite material) dan material keras buatan sintetis atau tiruan (Synthetic material).

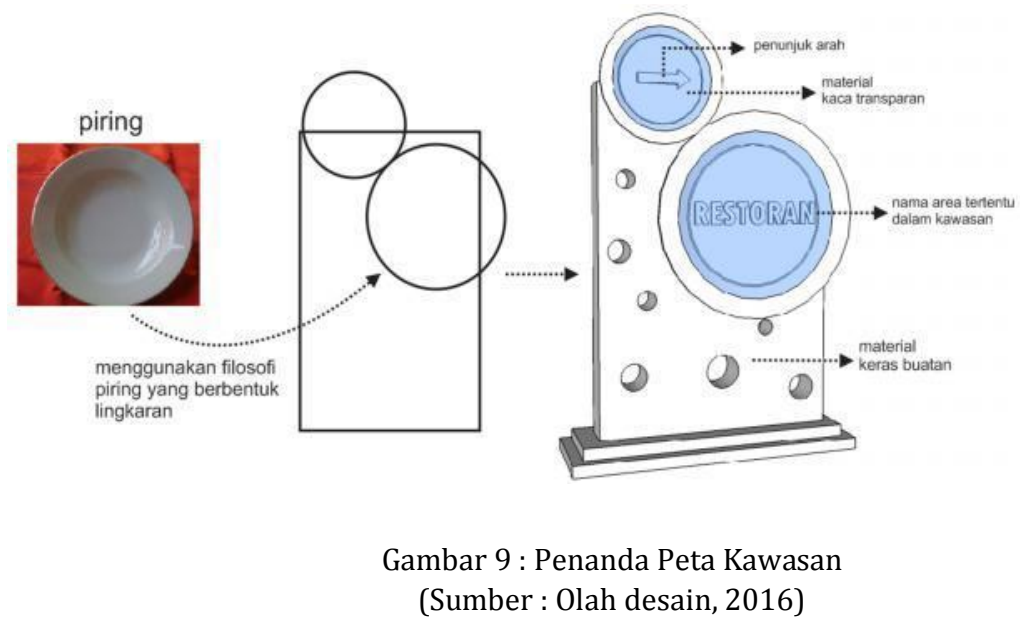

\section{G. Pemanfaatan Lahan}

Persentase pemanfaatan lahan didalam kawasan taman wisata kuliner lokal terdiri dari lahan terbangun dan ruang terbuka adalah sebagai berikut:
a. Bangunan utama (Restoran) dengan luas
$=478 \mathrm{~m}^{2}$
b. Bangunan kios/ retail dengan luas
$=386 \mathrm{~m}^{2}$
c. Toilet umum dengan luas
$=51 \mathrm{~m}^{2}$
d. Bangunan penerima dengan luas
$=109 \mathrm{~m}^{2}$
e. Mini galeri kuliner dengan luas
$=184 \mathrm{~m}^{2}$
f. Amphitheather dengan luas
$=199 \mathrm{~m}^{2}$
g. Toko souvenir dengan luas
$=162 \mathrm{~m}^{2}$
h. Bangunan pengelola dengan luas
$=237 \mathrm{~m}^{2}$ 
i. Mushollah dengan luas

j. Penginapan dengan luas

k. Mekanikal elektrik dengan luas

l. Parkir dengan luas

m. Pos jaga dengan luas

n. Area gazebo dengan luas

o. Taman bermain dengan luas

Jumlah keseluruhan yang terbangun

$$
\begin{aligned}
& =187 \mathrm{~m}^{2} \\
& =30 \mathrm{~m}^{2} \\
& =38 \mathrm{~m}^{2} \\
& =4.000 \mathrm{~m}^{2} \\
& =27 \mathrm{~m}^{2} \\
& =286 \mathrm{~m}^{2} \\
& =355 \mathrm{~m}^{2} \\
& =6.729 \mathrm{~m}^{2}
\end{aligned}
$$

Dari data diatas diperoleh kesimpulan sebagaiberikut:

Luas total tapak perancangan yakni $=3.448,346 \mathrm{~m}^{2}$

Luas total hasil desain tapak yakni $=6.729 \mathrm{~m}^{2}$

Luas ruang terbuka $=$ luas tapak $(20 \%$ sirkulasi $)$ - luas terbangun

$$
\begin{aligned}
& =25.000 \mathrm{~m}^{2}-5000 \mathrm{~m}^{2}-6.729 \mathrm{~m}^{2} \\
& =13.271 \mathrm{~m}^{2}
\end{aligned}
$$

$\begin{array}{ll}\text { Persentase ruang terbuka } & =13.271 \mathrm{~m} 2 / 25.000 \mathrm{~m} 2 \times 100 \%=53,084 \% \\ \text { Persentase terbangun } & =6.729 \mathrm{~m} 2 / 25.000 \mathrm{~m} 2 \times 100 \%=26,916 \% \\ \text { Persentasi sirkulasi } & =5.000 \mathrm{~m} 2 / 25.000 \mathrm{~m} 2 \times 100 \%=20 \%\end{array}$

\section{H. Bentuk dan Massa Bangunan (Building From And Massing)}

Bentuk bangunan dalam desain kawasan disesuaikan dengan fungsi kawasan sebagai tempat wisata kuliner. Menurut Konnemann (Surya, 2013:10) ciri-ciri Arsitektur Kontemporer adalah: Ekspresi bangunan bersifat subjektif, Kontras dengan lingkungan sekitar, Bentuk simple tapi terkesan kuat. Citra/ karakter desain perencanaan kawasan taman wisata kuliner di Enrekang mengambil filosofi dari bentuk alat makan, hal ini dipilih karena sesuai dengan fungsi kawasan sendiri yaitu sebagai tempat untuk berwisata kuliner khas Enrekang selain itu dengan penggunaan bentuk ini akan memberikan image bagi kawasan sebagai tempat untuk menikmati kuliner.

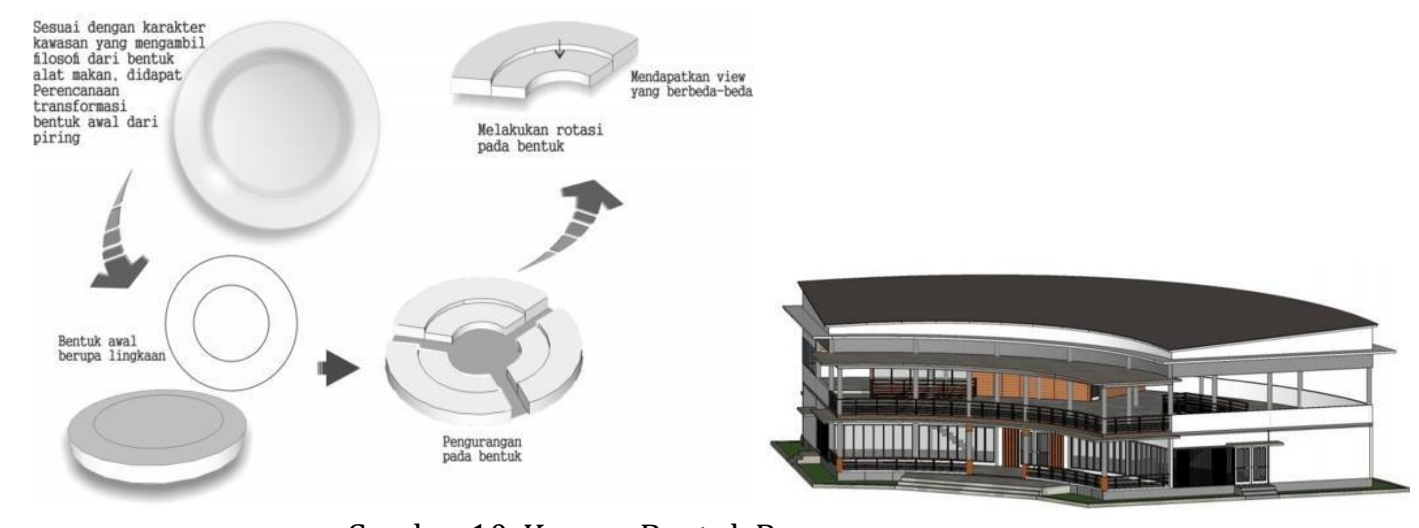

Gambar 10. Konsep Bentuk Bangunan

(Sumber: Olah Desain, 2016)

Penerapan tema arsitektur kontemporer kedalam konsep perancangan taman wisata kuliner bertujuan untuk menyesuaikan desain perancangan dengan yang berkembang saat ini. Untuk mewujudkan rancangan taman wisata kuliner dengan 
bertema arsitektur kontemporer dapat dicapai dengan menerapkan unsur-unsur yang berkesan modern dalam desain.
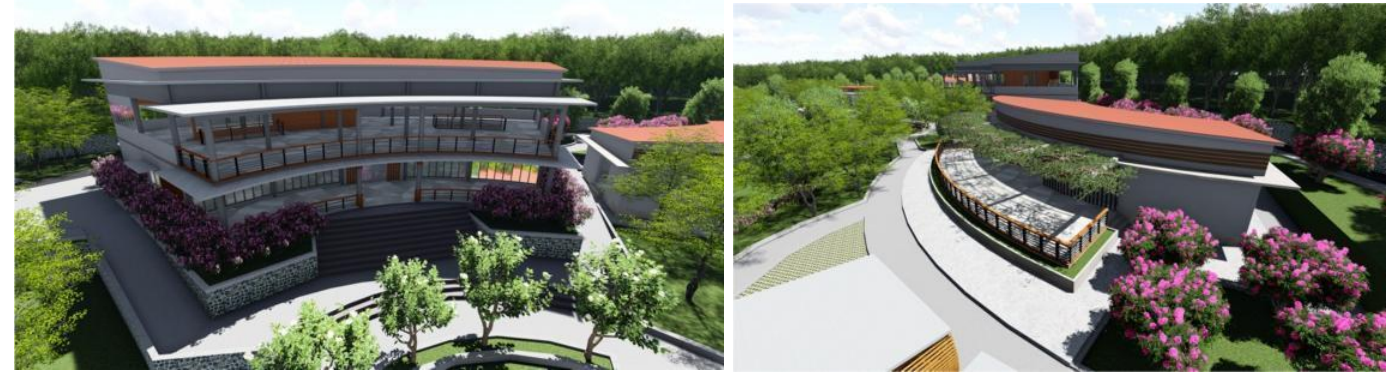

Gambar 11: Perspektif Banguanan Utama

Sumber : Hasil Desain (2015)
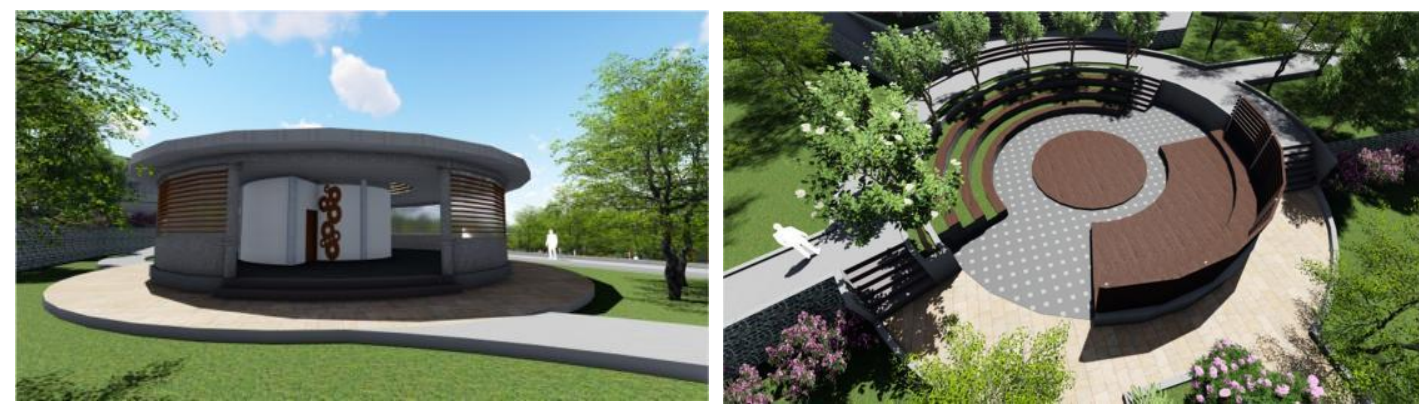

Gambar 12: Perspektif Mini Galeri Kuliner dan Amphiteather Sumber : Hasil Desain (2015)
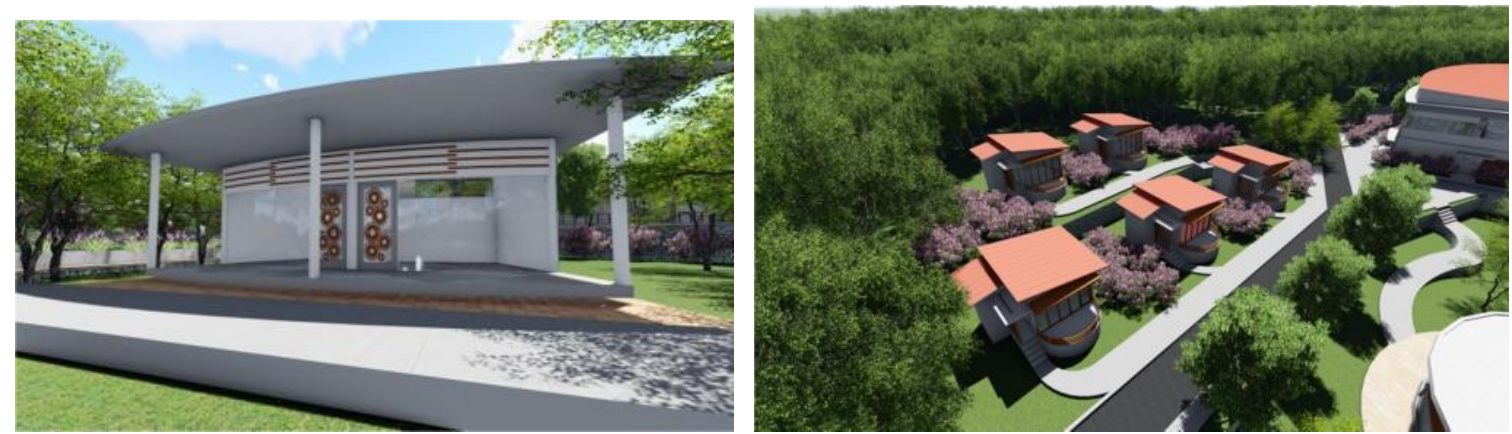

Gambar 13: Toko Souvenir dan Area Penginapan Sumber : Hasil Desain (2015)

Menurut Pandu (2011:13), dalam perancangan taman perlu dilakukan pemilihan dan penataan secara detail elemen-elemennya,agar taman dapat fungsional dan estetis. Bentuk Sclupture mengadopsi bentuk piring yang disusun secara vertikal kemudian dibagian atasnya terdapat gelas. Diletakkan di depan pintu masuk. Material yang digunakan dari material keras buatan kombinasi (Composite Material) 


\section{PERENCANAAN DAN PERANCANGAN TAMAN WISATA KULINER DI
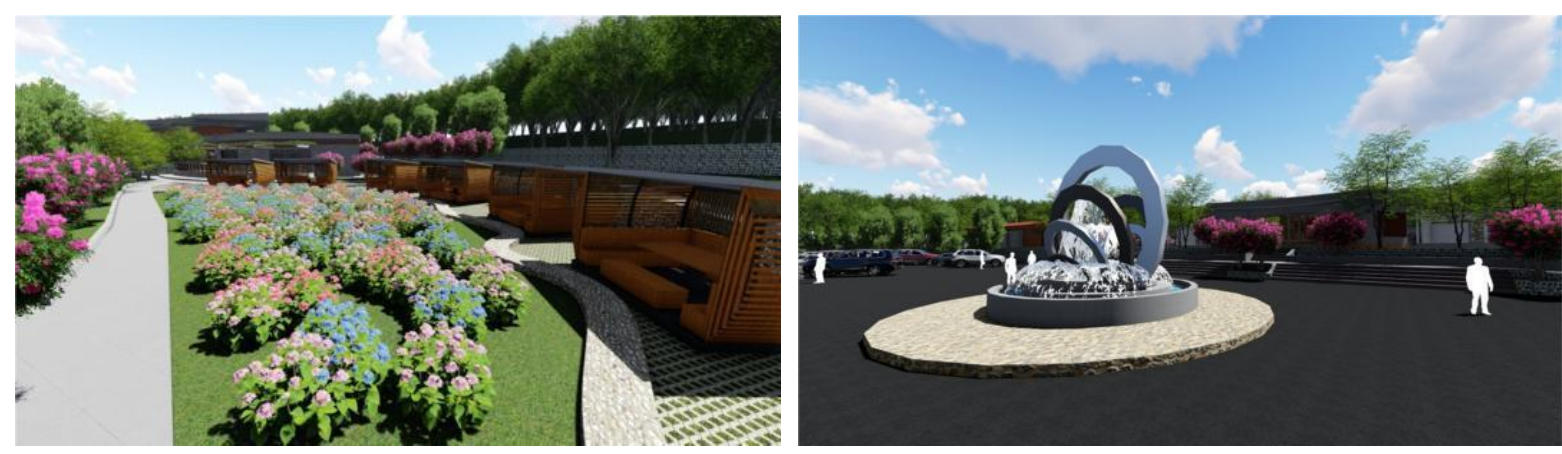

Gambar 14 : Gazebo dan Sculpture Kawasan Sumber : Hasil Desain (2015)

\section{KESIMPULAN}

Dari hasil kajian literatur dan faktual serta hasil analisis maka dapat disimpulkan beberapa hal tentang perancangan taman wisata kuliner di Kabupaten Enrekang, yaitu:

1. Perancangan kawasan taman wisata kuliner di Kabupaten Enrekang ini memuat 8 (delapan) elemen perancangan kota sebagai pedoman dalam merancang sebuah kota yaitu: Land Use, Building From and Massing, Circulation and Parking, Open Space, Pedestrian Ways, Activity Support, Signage, Preservation

2. Penentuan tapak didasarkan pada pansa pasar kawasan yaitu akses menuju lokasi sangat mudah, dan berada di depan jalan poros Makassar-Tator (Tanah Toraja) dan hal utama dalam pemilihan lokasi adalah suasana yang ditawarkan sekitar lokasi masih asri dengan panorama indah Gunung Nona dan Gunung Bambapuang yang sudah di kenal sampai ke mancanegara.

3. Dalam menentukan zoning taman wisata kuliner perlu memahami potensi serta masalah yang ada di kawasan. Kabupaten Enrekang memiliki jenis penggunaan lahan yang beragam. Jenis pengguanaan lahan pada kawasan diantaranya merupakan kawasan permukiman, kawasan wisata alam, perdagangan, hutan, kebun/ladang dan lahan kosong kemudian dibagi dengan tiga zona yaitu public, zona semi publik dan zona privat.

4. Dalam mendesain taman wisata kuliner dengan konsep Arsitektur Konteporer menjadi konsep perancangan yang baik karena bangunan lebih berkesan modern dan komersial. Filosofi bangunan dari bentuk alat makan, hal ini dipilih karena sesuai dengan fungsi kawasan sendiri yaitu sebagai tempat untuk berwisata kuliner khas Enrekang selain itu dengan penggunaan bentuk ini akan memberikan image bagi kawasan sebagai tempat untuk menikmati kuliner. 


\section{DAFTAR REFERENSI}

Adisasmita, Rahardjo. (2010). Pengembangan Kawasan dan Tata Ruang. Yogyakarta: Graha Ilmu.

Alamsyah, Yuyun. (2008). Bangkitnya Bisnis Kuliner Tradisional. Jakarta: PT. Elex Media Komputindo Kelompok Gramedia.

A'raaf, Fahmyddin, Tauhid. (2012). Perancangan Kota Ramah Bencana. Makassar: Alauddin University Press.

Arafat, Surya. (2013). Solo Technopark. Skripsi Sarjana, Fakultas Teknik Universitas Muhammadiyah Surakarta. Badan Pusat Statistik Kabupaten (BPS) Enrekang

Erwin, Lilly T. dan Abang Erwin. (2008). Peta 100 Tempat Makan Makanan Khas Daerah. Jakarta: PT. Gramedia Pustaka Utama.

Hall, Colin Michael, et al.( 2003). Food Tourism Around The World: Development, Management And Markets. New York.

Jahid, Jamaluddin. (2014). Perencanaan Kepariwisataan. Makassar: Alauddin University Press.

Muljadi A.J. (2009). Kepariwisataan dan Perjalanan. Jakarta: PT. Raja Grafindo Persada.

Rasmi, Retno R, et al. 2013. Arsitektur Kontemporer (MK: Teori Desain Arsitektur). Sekolah

Arsitektur, Perencanaan dan Pengembangan Kebijakan, Istitut Teknologi Bandung. Republik Indonesia. 2007. Peraturan Mentri Kebudayaan dan Pariwisata tentang Kriteria dan Penetapan Destinasi Pariwisata Unggulan.

Saleh, Zulkarnain. (2011). Wisata Kuliner Di Pantai Barombong Makassar. Skripsi Sarjana, Fakultas Sains dan Teknologi Universitas Islam Negri Alauddin Makassar.

Salim, Yusuf. 2013. Kamus Lengkap Bahasa Indonesia. Jakarta: Widyatama

Santosa, Arif. (2014). Kamus Umum Bahasa Indonesia. Jakarta: Mahkota Kita.

Suhamdani H, Hidri. (2010). Analisis Pengembangan Pariwisata Alam Lewaja Di Kabupaten Enrekang. Skripsi Sarjana, Fakultas Ilmu Sosial dan Ilmu Politik Universitas Hasanuddin Makassar.

Suharso dan Ana Retnoningsih. (2005). Kamus Besar Bahasa Indonesia Edisi Lux. Semarang: Widya Karya.

http://makassar.antaranews.com/print/10211/geliat-pariwisata-enrekang- menanti-wisatawan, (diakses 17 Maret 2015) 